\title{
O MARCO REGULATÓRIO DAS ORGANIZAÇÕES DA SOCIEDADE CIVIL: TERCEIRO SETOR E AS ORGANIZAÇÕES DE PEQUENO E GRANDE PORTES
}

\author{
Anderson Andrade de Araújo ${ }^{1}$ \\ Naiana Luiza Lourenço de Souza e Lira
}

RESUMO: O presente artigo trata sobre o novo Marco Regulatório das Organizações da Sociedade Civil implementado pela Lei Federal 13.019/2014, que estabelece o regime jurídico das parcerias entre a Administração Pública e as Organizações da Sociedade Civil. Nessa perspectiva é apresentado o conceito, surgimento, evolução histórica e os movimentos sociais que deram origem ao Terceiro Setor no Brasil, bem como a definição de Organização da Sociedade Civil. Após isso, será analisada os principais pontos dessa Lei e sua aplicabilidade. A pesquisa tem por objetivo esclarecer se a Lei trouxe benefícios para as organizações, o que mudou e como era antes para as organizações de pequeno e grande portes.

Palavras-chave: Marco regulatório. Terceiro setor. Organizações.

ABSTRACT: This article deals with the new Regulatory Framework for Civil Society Organizations implemented by Federal Law 13,019/2014, which establishes the legal framework for partnerships between Public Administration and Civil Society Organizations. From this perspective, the concept, emergence, historical evolution and social movements that gave rise to the Third Sector in Brazil are presented, as well as the definition of Civil Society Organization. After that, the main points of this Law and its applicability will be analyzed. The research aims to clarify whether the Law has brought benefits to organizations, what has changed and what it was like before for small and large organizations.

Keywords: Regulation mark. Third sector. Organizations.

\section{INTRODUÇÃO}

O Marco Regulatório das Organizações da Sociedade Civil: Terceiro Setor e as organizações de pequeno e grande portes é o tema central deste estudo. A delimitação do tema surgiu a partir da observação da Lei 13.109/2014 que estabeleceu o

\footnotetext{
${ }^{1}$ E-mail: naianaluiza@yahoo.com.br.

2 E-mail: andersonteleco@yahoo.com.br.
} 
regime jurídico das parcerias entre a Administração Pública e as Organizações da sociedade Civil e define diretrizes para a política de fomento, de colaboração e de cooperação com organizações da sociedade civil.

A Lei teve diferentes momentos de entrada em vigor, em 23 de janeiro de 2016 na União, Estados e Distrito Federal, e Municípios a partir de Io de janeiro de 2017; e foi celebrada como uma grande conquista para o Terceiro Setor.

Diante dessa questão, o objetivo deste artigo é identificar por meio da Lei 13.019/2014, a existência de uma conexão entre o que estabelece as diretrizes de implementação dos convênios e parcerias, bem como, se essas diretrizes facilitaram e/ou desburocratizaram essa parceria entre a Administração Pública e as Organizações da Sociedade Civil. A pesquisa possui natureza descritiva/exploratória.

A estratégia de construção da pesquisa foi alicerçada predominantemente sob o método qualitativo que, segundo Pereira et. Al (2018, p. 67), "este método é um caminho para se realizar a análise de algum fenômeno e, quando se tem o caminho, torna-se mais fácil realizar viagens sabendo o ponto de partida, o ponto de chegada e como fazê-lo". Esses métodos qualitativos são aqueles nos quais é importante a interpretação por parte do pesquisador com suas opiniões sobre o fenômeno em estudo. Neles a coleta de dados muitas vezes ocorre por meio de entrevistas com questões abertas ou leitura de obras amplas e diversificadas.

Este artigo está estruturado em três etapas distintas: na primeira etapa buscou-se os fundamentos conceituais do tema, surgimento, evolução histórica e os movimentos sociais que deram origem ao Terceiro Setor no Brasil, bem como a definição de Organização da Sociedade Civil.

Portanto, tratou-se de uma etapa conceitual, na qual a análise histórica foi predominante. Na segunda etapa, construiu-se o embasamento legal, partindo da análise da Lei no 13.019/2014, que é considerada o Marco Regulatório das Organizações da Sociedade Civil e complementada por outras legislações criadas para a formação do objeto de estudo. 
Já na terceira etapa, procurou-se identificar as diretrizes contidas na legislação, a realidade existente na implementação das parcerias e as inovações que a Lei proporcionou e os seus desdobramentos na realidade das organizações brasileiras, e se houve dificuldades no preenchimento dos requisitos, bem como, na captação de recursos e parcerias com o Poder Público, promovendo uma discussão sobre estas perspectivas, visando elucidar a questão problema e atingir o objetivo proposto.

\section{O TERCEIRO SETOR}

O conceito de Terceiro Setor foi construído ao longo do tempo por diversos autores, mas para Pietro (2015, p. I.138) ele "é composto por entidades da sociedade civil de fins públicos e não lucrativos”. São organizações privadas sem objetivo de lucro, ligadas às questões sociais. O Terceiro Setor complementa o Primeiro e o Segundo Setor, que é o Estado e o mercado respectivamente.

O Terceiro Setor, segundo Pietro:

"Caracteriza-se por prestar atividade de interesse público, por iniciativa privada, sem fins lucrativos; precisamente pelo interesse público da atividade, recebe proteção e, em muitos casos, ajuda por parte do Estado, dentro da atividade de fomento." (2015, p. 1.138).

Teve sua origem nos movimentos mundiais "cujo objetivo era suprir certa deficiência nas áreas de educação, saúde, cultura e meio ambiente” (Voese, Reptczuk, 20II, p. 32).

As organizações surgem em um momento que o Estado sozinho não consegue lidar com a grande demanda social. O Terceiro Setor é considerado por Voese, Reptczuk como um "impulsionador de iniciativas voltadas para o desenvolvimento social” (2011, p. 33).

$\mathrm{O}$ mundo passa por grandes transformações ao longo do século $\mathrm{XX}$, grande crescimento na economia com desenvolvimento na área agrícola, industrial, inovações tecnológicas, entre outras. Porém, aliado a isso há um considerável aumento da pobreza, desigualdade e conflitos de ordem étnica, religiosa, social, dentre outras. 
A partir de então, percebe-se que o Estado é ineficiente nessas questões e que não consegue atuar nessas demandas de ordem social e o Terceiro Setor por meio das organizações se mobiliza para atuar exatamente onde o Estado é falho.

No Brasil, a década de 1990 foi sobremaneira, "um período de grandes transformações econômicas e políticas que contribuíram para o redesenho de modelo de gestão pública e de estruturação do Estado" (Carvalho, Fadul, 2012, p. I49).

Após passar por anos de colapso na economia, o país parece começar a entrar em um processo de reestruturação da economia, mas ainda tem que enfrentar grandes desafios no que diz respeito a questões sociais.

Aliás, esse processo de crescimento segundo Carvalho e Fadul "embora economicamente relevantes, não contribuíram para a superação da pobreza e dos problemas sociais históricos”. (2012, p. 149). Com o aumento da pobreza, houve um protagonismo das organizações não governamentais, intervindo na sociedade ajudando essa parcela da população que necessitava de atenção.

Assim, o Terceiro Setor foi ganhando espaço e cada vez mais se teve à percepção da importância deste para o Estado e para a sociedade. Houve um crescimento exponencial do setor, "inclusive, pela perspectiva de financiamento de agências internacionais que reconheceram nas ONGs brasileiras potencial para desenvolver projetos em áreas prioritárias”. (Carvalho, Fadul, 2012, p. I49).

\section{I. O PROCESSO DE DESENVOLVIMENTO DAS ONGs E AS MUDANÇAS ADVINDAS COM O MARCO REGULATÓRIO}

As organizações não governamentais ganharam um papel de destaque no Brasil, a partir da década de 1990, captando recursos e atraindo investimentos de vários setores do mercado. Houve uma profissionalização da gestão das ONGs, com capacitação profissional, de maneira que, muitas ONGs tornaram-se verdadeiras empresas.

Todavia, nem todas as ONGs conseguem manter ou até mesmo chegar a um padrão de excelência satisfatório. $O$ que faz com que algumas delas não consigam captar recursos públicos e investimentos de empresas privadas. Nesse contexto, 
percebe-se que ONGs menores, sem profissional qualificado, deixam de receber recursos e investimentos, o que inviabiliza o funcionamento da mesma.

Muitas ONGs já nascem a partir de um projeto pré-concebido, ou até mesmo, com um orçamento aprovado de uma empresa maior que tem como objetivo a criação de uma fundação privada. Por isso a crítica de enquadrar todas as entidades privadas sem fins lucrativos como organização da sociedade civil, pois os objetivos podem não convergir.

Essa discussão é enriquecida quando se coloca os números de ONGs e OSCs ativos no Brasil, e se questiona o quão o Estado tem regulado, normatizado e principalmente fiscalizado essas entidades? A postura do Estado, nessa nova conjuntura, tem sido alvo de críticas principalmente por ter sido negligente e/ou talvez conivente em abrir espaços para abrigar grupos de pressão e lobbies, em lançar mãos de verbas públicas, direcionando-as para interesses de alguns.

É com esse intuito que o Poder Público desvirtua o convênio e/ou termo de cooperação com as OSCs de pequeno porte, pois diz que não preenchem os requisitos da Lei no 13.019/14 para recebimento de verbas públicas, sob o argumento de falta de capacidade técnica, gerencial e mão-de-obra suficiente.

Nesse panorama, a sociedade tem que estar atenta e cobrar respostas plausíveis nos convênios e cooperações sob suspeitas, denunciando aos órgãos de controle e fiscalizatório, como Ministério Público Estadual e Federal, Tribunais de Contas Estaduais e da União, Controladorias e o próprio órgão correcional do Poder Executivo. As ONGs de pequeno porte são presença fundamentais na interlocução de políticas públicas com o Estado para implantar programas de desenvolvimento social, luta contra o racismo, xenofobia, questões urbanas, meio ambiente, entre outros.

Diante de tantos percalços, houve a necessidade de um debate das parcerias entre a Administração Pública e as Organizações da Sociedade Civil, o que findou com a criação do Marco Regulatório das Organizações da Sociedade Civil, ou seja, a aprovação da Lei no 13.019/2014 


\title{
3 AS OSCs, A AGENDA POLÍTICA DO MROSC E O PROCESSO DE CRIAÇÃO DA LEI 13.019/2014
}

As Organizações da Sociedade Civil são entidades privadas sem fins lucrativos, ou seja, que não almejam lucro em suas atividades. Desenvolvem-se sem o objetivo de distribuição de resultados entre os associados.

Organizam-se em associações, fundações, organizações religiosas e cooperativas que trabalham com vulnerabilidade social, combate a pobreza e geração de renda, com previsão legal no Código Civil Brasileiro, com exceção das cooperativas que são reguladas pela Lei $9.867 / 99$ ou 5.764/7I.

Para melhor entender o processo de criação da Lei no 13.019/2014, conhecida como Marco Regulatório das Parcerias entre Estado e Organização da Sociedade Civil, faz-se necessário entender que MROSC é um

\begin{abstract}
conjunto de ações, atos normativos e instrumentos que estabelece o regime jurídico das parcerias entre a administração pública e as Organizações da Sociedade Civil (OSC), na perspectiva de superar o ambiente de insegurança jurídica, reconhecendo as peculiaridades dessas organizações e favorecendo a implementação de parcerias mais efetivas, a transparência na aplicação dos recursos públicos e o fortalecimento das OSC. (CONFOCO, 2019).
\end{abstract}

Superados esses conceitos, é necessário contextualizar as relações estabelecidas entre Estado e OSCs desde a promulgação da Constituição Federal de I988 até sua vigência, nas suas fases normativas distintas. Posteriormente, aprofundar as etapas da agenda do MROSC, desde suas primeiras reuniões em 2olI, até sua entrada em vigor.

A chamada fase da redemocratização, tem-se como marco o período de efetivação da garantia dos direitos à liberdade de criação dessas entidades. $O$ texto constitucional em seu art. $5^{\circ}$, inciso XVIII, para assegurar a necessária liberdade de reunião pacífica e liberdade de associação, previu a não interferência estatal na criação, funcionamento e auto-organização dessas organizações. 
E assim trouxe a garantia ao livre exercício dos direitos civis e políticos, em que o bem jurídico tutelado é o direito subjetivo de cada cidadão em participar de atividades lícitas voltadas à finalidade que lhe melhor atender.

$\mathrm{Na}$ fase subsequente, observa-se no plano constitucional, um controle da participação e controle social de representantes de OSCs no processo de elaboração, implementação e avaliação de políticas públicas. Isso foi fundamental na maior presença e atuação da sociedade civil no campo de Políticas Públicas e, apesar dos desafios dessa participação, apresenta-se como mecanismo de controle social das políticas de gestão pública.

De outra senda, temos a fase da produção de normas voltadas à regulamentação das relações jurídicas revertidas na forma contratual entre Organizações da Sociedade Civil e o Estado. Foi nela que se editaram a Lei no 9.637/98 (Lei das Organizações Sociais) e a Lei no 9.790/99 (Lei das OSCIPs) para as referidas relações de cooperação entre o Estado e OSCs.

Já na fase mais avançada, após inúmeros casos de desvios de recursos públicos - que culminou com a suspensão do Decreto no 7.568/20II, que previa os repasses a todas as entidades privadas sem fins lucrativos - medidas de controle na execução de convênio e/ou cooperação da União com as OSCs foram adotadas, principalmente na observância das regras da Lei no 8.666/93 (Lei de Licitações), como por exemplo, a previsão de suas modalidades, bem como idoneidade dos participantes no processo licitatório, publicidade, transparência, fiscalização e dotação orçamentária.

$\mathrm{Na}$ fase final, temos aquela com escopo administrativo, no qual tem o programa do Marco Regulatório das Organizações da Sociedade Civil como o caminho a ser trilhado pela Administração Pública no intuito de conhecer com profundidade as características, o papel e plano de atuação das OSCs como sujeitos importantes no desenvolvimento social nas áreas a elas vinculadas.

\section{I. O Programa do Marco Regulatório das Organizações da Sociedade Civil e seus ideais}


Diante dos anseios das classes representativas de diversas organizações, movimentos sociais das mais variadas frentes e segmentos, que atuam, por exemplo, na promoção e defesa de direitos, na responsabilidade social ou em áreas tradicionais, como saúde, habitação, educação e assistência social.

Foi observado um engajamento em conjunto dos diversos atores dessa agenda pública nacional, entre eles, os agentes políticos, os órgãos de controle, estudiosos, parlamentares, advogados, promotores e defensores, no intuito de pautar a relevância do papel estatal como agente político-normativo de fomento e colaboração com as Organizações da Sociedade Civil.

Nesse diapasão, na agenda do MROSC, o ambiente proporcionou aprofundamento, trocas e alinhamento de informações no tema da sustentabilidade, certificação e contratualização, o que concretamente direcionou à elaboração de proposta do texto da Lei no 13.019/2014.

Esta também conhecida como "Lei de Fomento e de Colaboração" foi criada para estabelecer o regime jurídico das parcerias entre a Administração Pública e as OSCs; surgiu frente à necessidade de o Estado aperfeiçoar o esteio jurídico e institucional relativo às parcerias com as Organizações da Sociedade Civil.

Umas das principais contribuições do MROSC foi justamente de mesclar a importância e papel das OSCs combinado com a transparência na aplicação de recursos públicos, e um dos exemplos mais comuns são as $O \mathrm{NG}^{\prime}$ s. No entanto, o que se vê na prática destoa com os ideais do regulamento, seja pela dificuldade em dar tratamento igualitário as organizações, desvirtuamento do interesse social, desvios de recursos públicos, entre outros.

Portanto, a agenda política do MROSC contribuiu para elevar à discussão da parceria entre a Administração Pública e as OSCs no tocante às políticas públicas de relevância nacional, seja na questão do meio ambiente, de assistência social, de raça e gênero, sem deixar de cumprir os ditames e princípios constitucionais da legalidade, transparência, moralidade (art. $2^{\circ}$ da Lei).

\section{O MARCO REGULATÓRIO E SUAS PECULIARIDADES}


O marco regulatório foi recebido como uma grande conquista da sociedade. Ele estabelece um novo regime jurídico das parcerias entre a Administração Pública e as Organizações. A partir da Lei 13.019/14 são criados novos instrumentos jurídicos, os termos de fomento e colaboração para parcerias com recursos financeiros e os acordos de cooperação em parcerias sem recursos financeiros.

O grande destaque desse marco regulatório é o aperfeiçoamento da relação entre Estado e as Organizações da Sociedade Civil. Para isso, foram estabelecidos critérios jurídicos e organizacionais, com diretrizes voltadas a uma gestão pública democrática para o fortalecimento das organizações.

As principais mudanças foram os instrumentos jurídicos próprios, que são os termos de fomento, termo de colaboração e acordo de cooperação. O chamamento público que é obrigatório, objetivando transparência e democratização do acesso às parcerias com editais.

Outra mudança interessante é a prestação de contas simplificada com foco no controle de resultados, o que antes previa regra única para qualquer objeto $e$ valor. A criação de um conselho nacional de fomento e colaboração, com finalidade de propor e apoiar políticas públicas e ações voltadas ao seu fortalecimento.

Um fator importante da Lei é a sua abrangência nacional, com as mesmas regras no âmbito federal, estadual ou municipal, mas não impede que seja dado tratamento distinto a Municípios ou Estados que assim necessitarem.

A universalização das organizações fez com que todas as entidades não governamentais englobassem o conceito de OSCs e assim os novos instrumentos jurídicos poderão ser celebrados por todos independente de qualificação ou certificação. Vale ressaltar que a Lei 13.019/14 revogou o título de utilidade pública, como forma de desburocratizar a relação entre Estado e organizações.

O MROSC veio atender os anseios da sociedade, com a finalidade de estreitar os laços entre as organizações e a Administração Pública, ou seja, uma forma de aproximar as organizações que atuam suprindo uma demanda do Estado para mais perto dele.

Embora a lei tenha entrado em vigor em data posterior, foram muitos os desafios para as organizações se adequarem às novas diretrizes da Lei Federal, 
principalmente no quesito de organização e captação de recursos e com a comunicação e transparência, tornando obrigatória a divulgação das parcerias celebradas.

A Lei 13.019/14 exige das OSCs mais planejamento em suas ações e comprovação de tempo mínimo de três anos de existência para celebração dos termos de parceria com a União, dois anos com Estados e Distrito Federal e um ano pelo menos com os Municípios, além de experiência, capacidade técnica, regularidade jurídica e fiscal.

É certo que as novas diretrizes trazidas pela lei foram comemoradas ao dar um tratamento igualitário a todos, reduzindo os riscos de fraudes e corrupção. Entretanto, há ressalvas nessa igualdade, pois as pequenas organizações, que não possui uma gestão profissionalizada podem se prejudicar frente às outras organizações que possui uma equipe de profissionais capacitados.

Portanto, esses requisitos exigidos podem ser uma barreira para as pequenas organizações firmarem parcerias e receberem recursos públicos inviabilizando o objetivo e a continuidade da OSC que possui em sua essência atividades voltadas para as questões sociais e das pessoas mais vulneráveis da sociedade.

\section{CONCLUSÃO}

A temática do novo Marco Regulatório das Organizações da Sociedade Civil é profunda e sistemática, observando-se na questão problema as novas diretrizes trazidas pela Lei Federal 13.019/14 e como ela foi recebida pelas organizações de diferentes padrões de tamanho e gestão.

Reforça-se assim o objetivo deste artigo que é identificar por meio dos fundamentos da Lei Federal, a existência de um alinhamento entre o que dispõe as diretrizes legais para a implementação dos novos instrumentos jurídicos, e a realidade existente nas OSCs brasileiras.

Sendo assim, entende-se que o estudo consegue dar maior clareza a questão problema e alcançar o objetivo proposto, ao evidenciar que os requisitos propostos ao mesmo tempo que dá um tratamento igualitários, ele coloca as pequenas 
organizações em desvantagem ao impor critérios técnicos, jurídicos e fiscais para concessão de recursos públicos.

Portanto, como limite deste estudo, não coube aprofundar o debate do tratamento igualitário dado a todas as organizações, independente do tempo de existência e tamanho, mas identificar a importância de avançar nesse tema, sem desvencilhar de questões macro da política voltada as questões sociais das OSCs nos

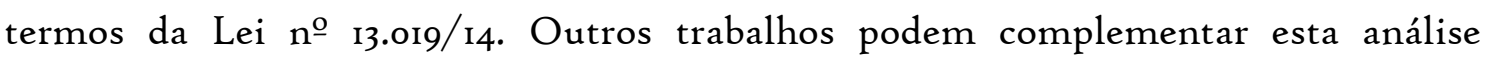
inicial.

Há poucos anos de vigência do MROSC, após os estudos e avaliações do tema, percebe-se que as organizações de pequeno porte são 'discriminadas' no nascedouro da própria Lei que a regulamenta, exigindo um debate dos atores envolvidos no tema, como políticos, sociedade civil, organismos nacionais e internacionais, para provocar audiências públicas e levantar propostas de alterações da Lei no 13.019/14 que sejam viáveis para a sobrevivência e atuação dessas organizações no Brasil.

\section{REFERÊNCIAS}

BRASIL, Constituição da República Federativa do Brasil. Disponível em: http://www.planalto.gov.br/ccivil_03/constituicao/constituicao.htm. Acesso em: julho 202I.

BRASIL, Lei n.o 9.637 , de 15 de maio de 1998. Dispõe sobre a qualificação de entidades como organizações sociais, a criação do Programa Nacional de Publicização, a extinção dos órgãos e entidades que menciona e a absorção de suas atividades por organizações sociais, e dá outras providências, 1998. Disponível em: http://www.planalto.gov.br/ccivil_03/leis/19637.htm. Acesso em: julho 2021.

BRASIL, Lei n.o 9.790, de 23 de março de 1999. Dispõe sobre a qualificação de pessoas 
jurídicas de direito privado, sem fins lucrativos, como Organizações da Sociedade Civil de Interesse Público, institui e disciplina o Termo de Parceria, e dá outras providências, I999. Disponível em: http://www.planalto.gov.br/ccivil_03/leis/l979o.htm. Acesso em: julho 202I.

BRASIL, Lei n. ${ }^{\circ}$ 8.666, de 2I de junho de 1993. Regulamenta o art. 37, inciso XXI, da Constituição Federal, institui normas para licitações e contratos da Administração Pública e dá outras providências, 1993. Disponível em: http://www.planalto.gov.br/ccivil_03/leis/18666cons.htm. Acesso em: julho 2021.

BRASIL, Decreto n. ${ }^{\circ}$ 7.568, de 16 de setembro de 2011. Altera o Decreto no 6.170, de 25 de julho de 2007, que dispõe sobre as normas relativas às transferências de recursos da União mediante convênios e contratos de repasse, o Decreto no 3.100 , de 30 de junho de 1999, que regulamenta a Lei no 9.790, de 23 de março de 1999, e dá outras providências, 20II. Disponível em: http://www.planalto.gov.br/ccivil_03/_atozoII2014/2011/decreto/D7568.htm. Acesso em: julho 2021.

BRASIL, Lei n.o 13.019, de 31 de julho de 2014. Estabelece o regime jurídico das parcerias entre a administração pública e as organizações da sociedade civil, em regime de mútua cooperação, para a consecução de finalidades de interesse público e recíproco, mediante a execução de atividades ou de projetos previamente estabelecidos em planos de trabalho inseridos em termos de colaboração, em termos de fomento ou em acordos de cooperação; define diretrizes para a política de fomento, de colaboração e de cooperação com organizações da sociedade civil; e altera as Leis nos 8.429, de 2 de junho de 1992, e 9.790, de 23 de março de 1999. (Redação dada pela Lei $\mathrm{n}^{\circ}$ 13.204, de 2015), 2014. Disponível em: http://www.planalto.gov.br/ccivil_03/_ato20II-2014/2014/lei/li30I9.htm. Acesso em: julho 202I.

CONFOCO, Conselho Estadual de Fomento e Colaboração. Implementação do Marco Regulatório das Organizações da Sociedade Civil (MROSC) Lei no. 
13.019/2014 Contribuição aos municípios baianos, 2019. Disponível em: http://www.confoco.serin.ba.gov.br/wpcontent/uploads/2019/o4/Contribui\% $\mathrm{C}_{3 \%}$ A 7\% $\mathrm{C}_{3 \%}$ B 5 es-aos-Munic\% $\mathrm{C}_{3} \%$ ADpios-Baianos-MROSC-2.pdf. Acesso em: julho 2021.

DI PIETRO, Maria Sylvia Zanella. Direito Administrativo. 33. ed. rev. e atual. Rio de Janeiro: Forense, 2020.

OLIVEIRA DE CARVALHO, A.; MIRIAN CAVALCANTI FADUL, E. Os Fatores Críticos de Sucesso na Gestão de Organizações Não Governamentais. Administração Pública e Gestão Social, [S. l.], v. 4, n. 2, p. I48-171, 2012. Disponível em: https://periodicos.ufv.br/apgs/article/view/4088. Acesso em: 26 jul. 2021.

PÁDUA, E. M. M. Metodologia da Pesquisa: Abordagem teórico-prática. São Paulo: Papirus Editora, 2016.

SUCUPIRA, Luciana Abranches. CHAVES, Alexandra Drabik. MONTEIRO, Maria Gabriela. ONGs e Estado: Entre a Retórica e a Prática Autoria. XXXI Encontro da ANPAD. Rio de Janeiro, 22 a 26 de setembro de 2007.

STORTO, Paula Raccanello. Questões de impacto federativo decorrentes do marco regulatório das Organinzações da Sociedade Civil e a Lei no 13.019/2014. Artigo publicado na Revista Brasileira de Direito do Terceiro Setor, n. 20 jul/dez 2016, Editora Fórum, São Paulo.

VOESE, S. B.; REPTCZUK, R. M. Características e peculiaridades das entidades do terceiro setor. Contabilidade em texto, [S. l.], v. II, n. 19, p. 31-42, 2011. Disponível em: https://seer.ufrgs.br/ConTexto/article/view/I63I4/pdf. Acesso em: 26 jul. 202I. 